\title{
La naissance d'un anachronisme : « le féminisme pendant la Révolution française »
}

\section{Christine Fauré}

\section{(2) OpenEdition \\ 1 Journals}

Édition électronique

URL : https://journals.openedition.org/ahrf/6433

DOI : 10.4000/ahrf.6433

ISSN : 1952-403X

Éditeur :

Armand Colin, Société des études robespierristes

Édition imprimée

Date de publication : 1 juin 2006

Pagination : 193-195

ISSN : 0003-4436

Référence électronique

Christine Fauré, «La naissance d'un anachronisme : « le féminisme pendant la Révolution

française » », Annales historiques de la Révolution française [En ligne], 344 | avril-juin 2006, mis en ligne le 01 juin 2009, consulté le 22 avril 2022. URL : http://journals.openedition.org/ahrf/6433 ; DOI :

https://doi.org/10.4000/ahrf.6433

Ce document a été généré automatiquement le 22 avril 2022.

Tous droits réservés 


\title{
La naissance d'un anachronisme : «le féminisme pendant la Révolution française ${ }^{1}$
}

\author{
Christine Fauré
}

\section{NOTE DE L'ÉDITEUR}

Transcription des lettres par Violaine Challéat, conservateur du patrimoine

1 Les néologismes féminisme et féministe apparaissent de manière sporadique dans le vocabulaire médical des années 1870 pour décrire une féminisation du corps et, sous la plume d'un écrivain à succès, Alexandre Dumas fils qui, dans son pamphlet L'hommefemme (1872), taxe de «féministes » les partisans de la cause des femmes. Dix ans plus tard, une journaliste, Hubertine Auclert, pionnière du suffragisme en France ${ }^{2}$, qualifie son combat de féministe. Avec la création d'une Fédération française des sociétés féministes en 1891 et une campagne européenne pour l'émancipation des femmes, cet usage des mots se popularise dans la décennie 1890-1900.

2 Le premier congrès annuel de la Fédération des sociétés féministes se tient en 1892 et bénéficie d'une importante couverture de presse. Le quotidien Le Temps suit l'événement du 14 au 17 mai. L'utilisation de ce terme se généralise en Europe, notamment en Belgique et dans la Suisse francophone. La Revue politique et parlementaire publie, à partir d'août 1896, une série d'articles sur le féminisme en Angleterre, France, Italie, États-Unis, Australie et Allemagne ${ }^{3}$. C'est dans ce contexte que François-Alphonse Aulard $^{4}$ (1849-1928), titulaire de la chaire d'histoire de la Révolution française à la Faculté de lettres de Paris depuis 1891, républicain, libre penseur, dreyfusard, membre du Parti radical, s'interroge sur l'existence d'un mouvement féministe pendant la Révolution française, scène originelle à ses yeux de la démocratie et de la république. Il profite d'une demande d'information que lui adresse l'historien Léopold Lacour (1854-1939), normalien, agrégé de lettres, professeur de rhétorique, conférencier, 
dramaturge et critique, pour amorcer une correspondance ${ }^{5}$ : le goût de l'éloquence les rapproche. En 1898, il s'enquiert avec une certaine inquiétude de la signification du mot féminisme. Aux yeux d'Aulard, Lacour est un interlocuteur possible bien que ce dernier ne se réclame pas du féminisme et dénonce dans son ouvrage L'Humanisme intégral, duel des sexes - la cité future (Paris, 1897), une utilisation abusive de ce terme : «Il m'était clair que le mot féminisme, d'ailleurs équivoque, ne rendait qu'une partie, la moins personnelle de ma pensée [...] On a vu naître, voilà deux ans un féminisme chrétien. Il y avait déjà et depuis longtemps un féminisme bourgeois et un féminisme socialiste ».

3 L'appellation d'« humanisme intégral » que Lacour propose ne fit pas souche et Aulard ne la reprend pas dans son article de la Revue Bleue qui représente le summum de son intérêt pour la cause des femmes : hommage au texte de Condorcet sur L'Admission des femmes au droit de cité, à l'action d'Etta Palm d'Aelders au sein de la Société fraternelle des deux sexes. En historien, il ne cède pas à la manie du portrait et souligne la dimension collective du mouvement avec ses limites : « Les femmes participèrent enfin à la Révolution qu'elles contribuèrent à faire réussir, celles-là dans les salons, celles-ci dans la rue, quelques unes à la prise de la Bastille. Elles concoururent par des paroles et par des actes, à la municipalisation de la France en juillet 1789. Ce sont des parisiennes qui firent les journées des 5 et 6 octobre, si décisives [...]. Elles avaient vraiment fait acte de citoyennes, lorsque Condorcet reprit en main leur cause, avec plus d'éclat et d'insistance qu'en 1788 ».

4 En 1902, une évolution dans la pensée d'Aulard se lit à travers l'appréciation qu'il porte sur le républicanisme de Mademoiselle de Kéralio : «Était-elle féministe? se demandet-il. Oui et non. C'est-à-dire qu'elle ne fit pas de thèse féministe mais partant de cette vue que la démocratie et la république, c'est la fraternité, elle crut que la fraternité devait reposer sur l'alliance de l'homme et de la femme pour l'œuvre sociale et politique $»^{6}$. À travers l'action de l'entreprenante journaliste que fut Mademoiselle de Kéralio ${ }^{7}$, les convictions d'Aulard se révèlent, liant indissolublement égalité des sexes et république, lien que les écrits de Mademoiselle de Kéralio, et l'histoire de France furent loin de confirmer.

\section{ANNEXES}

* St Palais-sur-Mer (Charente Inférieure), 24 septembre 1895

Monsieur et cher confrère,

Mes trois volumes sur l'Éloquence parlementaire pendant la Révolution sont épuisés, je n'en ai plus que mon exemplaire personnel, et je ne vois aucun moyen de vous le procurer, si ce n'est par les bouquinistes.

Quant au Culte de la Raison, il a paru chez Alcan, pour lequel je vous envoie le petit mot ci-joint.

Vos intéressantes questions s'adressent à quelqu'un qui est en bien mauvaise posture pour y répondre, loin de ses notes et de ses livres, le cerveau vide. 
Cependant je ne crois pas qu'il y ait de document rare et curieux sur votre sujet en dehors des sources que vous me paraissez si bien connaître. Vous savez que Tourneux ${ }^{8}$ n'a pas encore publié la partie de sa bibliographie relative à l'histoire des mœurs : elle vous serait fort utile. Une de vos sources utiles, c'est le club des Jacobins ${ }^{9}$. Mon tome V de « La Société des Jacobins » (janvier 1793-mai 1794) vient de paraître chez Cerf. Vous n'auriez qu'à le lui demander pour compte-rendu (sans vous croire tenu à rien pour cela).

Avez-vous retrouvé quelque registre d'un club de femmes? Ce serait très important. Les Tableaux de Paris pendant la Rév. par A. Schmidt ${ }^{10}$ sont précieux surtout avec la table alphabétique, qui forme un tome IV, lequel manque souvent aux exemplaires. Je ne parle pas de l'ouvrage édité chez Champion et traduit (je crois) par Viollet, mais du recueil de documents publié en français à Leipzig, et dont le dernier volume (la table) a paru en 1870 ou 1871.

Schmidt n'a pas donné tous ces rapports de police. Il y en a d'autres aux Archives, et au moins aussi importants.

Non, Lairtullier ${ }^{11}$ n'a pas été, que je sache, réimprimé.

La suppression des clubs de femmes par les Montagnards a été le premier acte par lequel ils ont commencé à réaliser leur plan de suppression de toutes les Sociétés populaires non jacobines. Ils ont ensuite supprimé les Sociétés sectionnaires. On voulait à tout prix l'unité dans le gouvernement de la défense nationale. C'est là un point de vue peut-être superficiel, mais non négligeable dans l'histoire du rôle des femmes pendant la Révolution. Je reviendrai à Paris à la fin d'octobre, et si vous désirez d'autres renseignements, je me mettrai à votre disposition pour en causer avec vous.

Veuillez agréer, Monsieur et cher confrère, l'expression de mes sentiments bien dévoués et sympathiques.

A. Aulard

Les Petites affiches ${ }^{12}$, patiemment feuilletées, sont une source précieuse pour l'histoire des mœurs pendant la Révolution, précieuse et très amusante.

* Paris, 19 nov. 97,

1 place de l'École

Cher monsieur,

Vous connaissez sans doute (mais je me permets de vous le signaler) le passage de

l'Essai sur les Assemblées provinciales par Condorcet ${ }^{13}$ (œuvres, t. IX, p. 141) où il

réclame le «droit de cité » pour les femmes (en 1788). Vous savez aussi que le

règlement pour la formation des assemblées provinciales accorde des droits politiques aux femmes seigneurs de paroisses, et que, pour la convocation des États généraux, certaines catégories de femmes votèrent.

Votre bien dévoué

A. Aulard

* Paris, 27 février 1898

1, place de l'École

Cher monsieur,

Dans mon cours à la Sorbonne, je traite cette année des origines du parti républicain. Ces origines sont intimement mêlées au mouvement féministe sous la Constituante. J'ai tâché de démêler cela, et j'ai été amené ainsi à faire toute une leçon, mercredi dernier, sur le féminisme en 1790-1791, leçon que je publierai sans doute en forme d'article. Mais je ne sais pas du tout ce qu'on a publié sur le même sujet, et j'ai recours à votre 
obligeance pour le savoir. Connaissez-vous un article ou une étude quelconque làdessus, qui vaille la peine d'être lus et cités ? Je sais que vous avez fait des conférences : ont-elles été publiées ? Le Faure ${ }^{14}$ et Lairtullier, voilà tout ce que je connais. Vous me feriez très grand plaisir en prenant la peine de me répondre un mot là-dessus, et voyez mon indécision! C'est une prompte réponse que je vous demande. Me voilà très intéressé par un sujet que je croyais n'aborder qu'en passant. Autre question, bien naïve et presque bête : féminisme, cela veut bien dire, n'est-ce pas ? une doctrine en vue d'égaler les droits de la femme à ceux de l'homme? je ne voudrais pas employer ce mot abusivement.

Veuillez agréer, cher monsieur, l'expression de mes sentiments bien dévoués et sympathiques.

A. Aulard.

[en tête : La « Révolution Française » / revue d'histoire moderne et contemporaine publiée par la société de l'Histoire de la révolution /cabinet du directeur / 1, place de l'École (Quai du Louvre)],

* Paris, le 20 janvier 1900

Cher monsieur,

Dans le Répertoire pour 1898, je vois seulement le livre de M. de Maulde : Les femmes de la Renaissance, chez Perrin, in-8 de 722 p., et deux articles sur ce livre, intitulés Le féminisme au XVIe siècle, l'un par Chantavoine, dans Le Correspondant, année 1898, l'autre par Doumic, dans la Revue des deux mondes, même année.

Je suis très fier et très heureux qu'une étude de vous me soit dédiée. Saviez-vous que le conventionnel Rouzet ${ }^{15}$ (de la Haute-Garonne) fut un féministe décidé ? En avril 1793 et en messidor an III, il réclame le droit de vote pour les femmes. Voir ses Vues civiques sur la Constitution, LE38-1506, in-8 [barré : pièce].

Votre cordialement dévoué,

Aulard

\section{NOTES}

1.Titre que François-Alphonse AULARD donne à son article de la Revue Bleue, $\mathrm{n}^{\circ} 12,19$ mars 1898, p. 331-366.

2. Voir sur ce sujet Geneviève FRAISSE, Muse de la raison, la démocratie exclusive et la différence des sexes, Aix-en-Provence, Alinéa, 1989, p. 198 ; Florence ROCHEFORT, « Du droit des femmes au féminisme en Europe », 1860-1914, dans Christine FAURÉ (éd), Encyclopédie politique et historique des femmes, Paris, PUF, 1997, p. 551-570 ; Karen OFFEN, European Feminisms, 1700-1950, A political history, Stanford, Cal, Stanford University Press, 2000, p. 183 et sq.

3.Revue politique et parlementaire, Paris, $\mathrm{n}^{\circ} 26$, août 1896, signé Millicent Garrett FAWCETT. $\mathrm{N}^{\circ} 38$, août 1897, signé Marya CHELIGA. $\mathrm{N}^{\circ} 39$, septembre 1897, signé Emilia MARIANI. $\mathrm{N}^{\circ}$ 45, mars 1898, signé M-S WolSTENHOLME. $\mathrm{N}^{\circ} 50$, août 1898, signé Harriet Hanson ROBINSON. $\mathrm{N}^{\circ} 58$, avril 1899, signé Lily BRAUM GIZYCKI. Le féminisme et la femme témoin, $\mathrm{n}^{\circ}$ 68 et 69,1900 , signé $F$. INGELBRECHT.

4.Voir AULARD, dans Dictionnaire biographique des historiens français et francophones, de Grégoire de Tours à Georges Duby, Christian AmAlvi (dir.), Paris, la Boutique de l'Histoire, 2004, p. 9. 
5.Bibliothèque Marguerite Durand, dossier Lacour, lettres manuscrites, boîte 2. Dans l'avant-propos de son ouvrage majeur, Les origines du féminisme contemporain, trois femmes de la Révolution, Olympe de Gouges, Théroigne de Méricourt, Rose Lacombe, Paris, Plon-Nourrit, 1900, Lacour remercie Aulard pour l'aide qu'il lui a apportée. Leur collaboration se poursuit avec la publication par Lacour de La Révolution française et ses détracteurs d'aujourd'hui, préface d'A. Aulard, Paris, Bibliothèque des réformes sociales, 1909. Sur la vie de Lacour, voir Léopold Lacour par Harlor, Paris, Bibliothèque internationale d'édition, 1914 ; Paroles d'amis, à la mémoire de Léopold Lacour, Paris, 1940. 6.François-Alphonse AULARD, Études et leçons sur la Révolution française, Paris, Alcan, 1902, p. 27.

7.Voir Christine FAURÉ, « Une histoire des femmes au XVIIIe siècle par Louise de Kéralio ", Revue de la Bibliothèque Nationale de France, $\mathrm{n}^{\circ}$ 17, " Femmes ", 2004, p. 61-64. 8. Maurice TOURnEux, Bibliographie de l'histoire de Paris pendant la Révolution française, tome III, « Monuments, mœurs et institutions », Paris, 1900.

9.F.A. AULARD, Société des Jacobins, recueil de documents pour l'histoire du club des Jacobins de Paris, tome V, janvier 1793-mars1794, Paris, Cerf, 1895.

10.Adolphe SCHMIDT, Tableaux de la Révolution française, publiés sur les papiers inédits du département et de la police secrète de Paris, Leipzig, Viet \& Co, 1867, 3 volumes. Le tome III, 1870 , contient une table alphabétique des matières qui contient, p. 25, de nombreuses références au mot « femmes».

11.E. LAIRTULLIER, Les femmes célèbres de 1789 à 1795 et leur influence dans la Révolution, pour servir de suite et de compléments à toutes les histoires de la Révolution française, Paris, 1840, 2 volumes.

12.Les Petites Affiches : il s'agit certainement des Affiches, annonces et avis divers ou Journal général de France[...]1783-1814, Paris.

13.Jean-Antoine-Nicolas de Caritat, marquis de CONDORCET (1743-1794), CEuvres publiées par A. Condorcet-O'Connor, Paris, Firmin Didot, 1847, tome huitième [et non tome IX], p. 141.

14.Amédée LE FAURE, Le socialisme pendant la Révolution (1789-1798), Paris, 1867. Le chapitre III est consacré aux droits de la femme, p. 117-168.

15.Jacques-Marie RouzET, Convention nationale. Vues civiques sur la Constitution que les Français sont intéressés à se donner, présentées par J.M. Rouzet, député de la Haute-Garonne à la Convention nationale, en messidor, l'an III de la République, imprimées par l'ordre de la Convention nationale. Aulard donne la cote de la Bibliothèque nationale. 